\title{
Research and practice of water source heat pump technology in Heyi station
}

\author{
Shiyao He ${ }^{1}$, Yongxiang Ren ${ }^{2}$, Kai Jiao ${ }^{3}$ Jun Deng ${ }^{4}$, Yiming Meng ${ }^{5}$, Le Liu ${ }^{6}$, Jinshuai $\mathrm{Li}^{7}$, Renjie $\mathrm{Li}^{8}$ \\ ${ }^{1}$ Engineering Technology Research Institute of Huabei Oilfield Company, Renqiu, Cangzhou,062552, China \\ ${ }^{2}$ Department of Technical Supervision and Inspection, Huabei Oilfield Company, Renqiu, Cangzhou,062552, P.R. China \\ ${ }^{3}$ No.1 oil production plant of Huabei Oilfield Company, Renqiu, Cangzhou, 062552, China \\ ${ }^{4}$ No.3 oil production plant of Huabei Oilfield Company, Hejian, Cangzhou, 062552, China \\ ${ }^{5}$ No. 3 oil production plant of Huabei Oilfield Company, Hejian, Cangzhou, 062552, China \\ ${ }^{6}$ No.1 oil production plant of Huabei Oilfield Company, Renqiu, Cangzhou, 062552, China \\ ${ }^{7}$ Erlian branch of Huabei Oilfield Company,Xilin Gol League,Inner Mongolia, 011200,China \\ ${ }^{8}$ Engineering Technology Research Institute of Huabei Oilfield Company, Renqiu, Cangzhou, 062552, China
}

\begin{abstract}
There are some problems in the thermal system of Huabei Oilfield, such as high energy consumption, high operation cost and poor production safety. With more stringent requirements for energy conservation and emission reduction, it is particularly important to replace fuel oil projects and improve the efficiency of heating system. The utilization of waste heat and waste heat resources in Huabei Oilfield and the application conditions of various heat pump technologies were investigated,according to the characteristics of large amount of sewage and high temperature produced by crude oil dehydration in Huabei Oilfield. Aiming at the characteristics of large amount of sewage and high temperature produced by crude oil dehydration in Huabei Oilfield, Pilot Application of Optimized Extracted Water Source Heat Pump Technology, the research results are applied to the the He Yi Station in the third oil production plant, estimating the scale and benefit of saving, finally, the purpose of reducing cost and increasing efficiency is achieved, and the data basis and technical guidance for energy saving renovation of thermal system in the future are improved.
\end{abstract}

\section{Introduction}

As more oilfields are developed, the energy consumption increases. This is particularly true in heavy oil development areas, where the thermal system accounts for over $70 \%$ of the total energy consumption. Oil gathering and transmission technique, a major technique in oilfield development, consists of steps including crude gathering, oil dehydration, crude stabilization and storage. The current oil gathering and transmission technique suffers such defects as low efficiency, large energy consumption and heavy pollution, taking up $30 \% \sim 40 \%$ of the total energy consumption. The oilfield will consume $15 \sim 35 \mathrm{~m}^{3}$ oil field gas for every tone of crude oil produced. As oilfield development enters the middle or late stage, the water content of the crude increases, the ratio of heavy oil rises, the temperature for crude oil dehydration climbs up, leading to a higher consumption of energy. During oil dehydration, large quantities of waste water of $30^{\circ} \mathrm{C} \sim 70^{\circ} \mathrm{C}$ will be produced. If the waste water flows back or discharges, it will cause waste of energies and "heat pollution". Therefore, to reduce the thermal power consumption in crude processing and find alternatives to the traditional oil gathering and transmission technique is of crucial importance to oil development.

\section{Technical principle of water source heat pump}

The water source heat pump (WSHP) is a technique that uses the low-temperature low-level heat generated in the surface water that takes in solar energy and geothermal energy to realize shift from low-level heat to high-level heat with small quantities of high-level heat input based on the heat pump principles. The heat pump can make use of low-quality waste water to provide heat required by the transmission of crude oil. The general efficiency of heat pumps is above $2 \sim 5$, far above 0.8 that is the average heat efficiency of heating furnaces. The performance of the heat pumps is gauged by the coefficient of performance (COP), which is defined as the ratio of the heat transferred from low-temperature objects to high-temperature objects to the required power. The COP of universal heat pumps is between 2 and 5 , that is, the pump can transfer heat two to five times of its own from low-temperature objects to high-temperature objects. Thus, the heat pump is in fact a heat improvement device which consumes a very small quantity of electrical power and extracts electrical power one to four times larger of its own from the surroundings (water, air, soil, etc.) to increase the temperature for utilization.

aemail: cy3_hsy@petrochina.com.cn, bemail: 61044772@qq.com 


\section{Application cases}

The Heyi Station of the Third Oil Development Plant was taken as the trial site to verify the heat pump optimization model. As the plant are well-equipped with oil gathering, dehydration and thermal processing equipment, there is no need to buy extra equipment, which considerably reduces the research expenditure.

The water processing workflow in the station: settlement, coalescence, flotation and filtering of the produced water, assisted physical sterilization, physical dust prevention, chemical treatment; when the processed water reaches the Third-level Water Quality specified in SY/5329-2012 Standards, reinjection is performed. The water is injected to the oil tank and then the stabilization tank, and after flotation, coalescence and filtering, the water is transferred to the injection tank.

a) Operations of the water source heat pump unit in Heyi Station

As of 13th March, 2019, the unit has served 1898 hours and has been started 44 times. As stated by the staff, the unit is in good service state.

The unit is equipped with properly installed sensors for temperature, stress and water flow, so the data used for evaluation are measured data from sensors on the unit. The power consumption of the unit is the accumulative value of 10 days. As the unit is in a stable state of service and has been always in service, the mean of the accumulative power consumption value is used instead of the instant values to assess the unit's performance.

b) Analysis of operating data of the heat pump unit in Heyi Station

According to the observed data during the period of assessment, the system's COP, heating capacity and power consumption under different temperatures of the waste water are analyzed.

The instant heating capacity of the system is obtained by calculating the temperature difference before and after the water flows through the condenser, as expressed by the following equation:

$$
Q_{c}=\rho V c_{p}\left(t_{h}-t_{g}\right)
$$

where Qc is the heat obtained by the unit $(\mathrm{kW}), \rho$ is the hot water density $\left(\mathrm{kg} / \mathrm{m}^{3}\right)$, and the approximate value 1000 $\mathrm{kg} / \mathrm{m}^{3}$ is adopted herein; $\mathrm{cp}$ is the isobaric specific heat capacity $(\mathrm{kJ} / \mathrm{kg} \mathrm{K})$, and the approximate value $4.2 \mathrm{~kJ} / \mathrm{kg} \mathrm{K}$ is adopted herein; th and tg represent the temperature of the returned water and the supplied water in the condenser, respectively.

The system's power consumption is expressed by the mean of the accumulative power consumption, as shown below:

$$
P=P^{*} /(24 n)
$$

where $\mathrm{P}$ is the power consumption of the unit $(\mathrm{kW}), \mathrm{P}^{*}$ is the total power consumption within $\mathrm{n}$ days $(\mathrm{kW} \cdot \mathrm{h})$

The unit's instant power consumption is calculated with the current and voltage of the unit measured at site, as shown below:

$$
P=\sqrt{3} U I \cos \varphi
$$

where $\mathrm{U}$ is the circuit voltage $(\mathrm{V})$, and $380 \mathrm{~V}$ is adopted herein; I is the current (A), and $\cos \psi$ is the power coefficient.

The range of changes in the temperature of the waste water during the measurement is $44.6^{\circ} \mathrm{C}-47.7^{\circ} \mathrm{C}$, and the range for hot water is $69.6^{\circ} \mathrm{C}-71.1^{\circ} \mathrm{C}$. The unit is in a stable state of service.

Table 1: Operation data of water source heat pump

\begin{tabular}{|c|c|c|c|}
\hline $\begin{array}{c}\text { Hot water } \\
\text { outlet } \\
\begin{array}{c}\text { temperature } \\
\left({ }^{\circ} \mathrm{C}\right)\end{array}\end{array}$ & $\begin{array}{c}\text { Hot water } \\
\text { inlet } \\
\text { temperature } \\
\left({ }^{\circ} \mathrm{C}\right)\end{array}$ & $\begin{array}{c}\text { Hot } \\
\text { water } \\
\text { flow } \\
\left(\mathrm{m}^{3} / \mathrm{h}\right)\end{array}$ & $\begin{array}{c}\text { sewage } \\
\text { outlet } \\
\text { temperature } \\
\left({ }^{\circ} \mathrm{C}\right)\end{array}$ \\
\hline 69.6 & 58.9 & 92.3 & 44.4 \\
\hline 70 & 58.8 & 92 & 44.8 \\
\hline 70.1 & 58.7 & 92 & 47.7 \\
\hline 70.6 & 59.3 & 92 & 44.8 \\
\hline
\end{tabular}

\begin{tabular}{|c|c|c|c|}
\hline $\begin{array}{c}\text { sewage inlet } \\
\text { temperature } \\
\left({ }^{\circ} \mathrm{C}\right)\end{array}$ & $\begin{array}{c}\text { Power } \\
\text { consumption } \\
(\mathrm{kW} \cdot \mathrm{h})\end{array}$ & $\begin{array}{c}\text { power } \\
(\mathrm{kW})\end{array}$ & COP \\
\hline 31.2 & - & 313.1 & 3.68 \\
\hline 28.9 & - & 254 & 4.73 \\
\hline 37.3 & - & 297 & 4.12 \\
\hline 33.7 & 5718 & 238 & 5.09 \\
\hline
\end{tabular}

c) Evaluation of economic efficiency

The unit has a COP value of 3.68 and is designed to work 8000 hours per year, with an average power load of 0.8 , and the electricity price is 0.7 yuan/ $\mathrm{kW} \cdot \mathrm{h}$. Two schemes are adopted to analyze the operating cost of the unit: one is using the water source heat pump, and the other is using the natural gas boiler. With the water source heat pump as the heat source, the yearly operating cost of the unit is 1.441 million yuan, while the cost is 3.2296 million yuan if the natural gas boiler is used. Therefore, the former scheme cuts the cost by 1.7886 million yuan.

\section{Heat pump technology used when the volume of produced water does not meet the needs for heat load}

This section explores the heat pump technology when the volume of produced water is small and the heat load need is large, and the regular technology does not meet the needs.

Technical route: the temperature drop is maximized, and the lingering temperature of the produced water after heat transfer is $4{ }^{\circ} \mathrm{C}$; no congestion occurs during water flooding in the winter, the output water temperature is 70 $\sim 75{ }^{\circ} \mathrm{C}$, and the COP is above 2 .

a) Increasing the area of the heat transferer of the produced water and reducing the temperature to $4{ }^{\circ} \mathrm{C}$ to meet the requirement for water flooding;

b) Optimizing the technique and connecting several heat pumps in series. Different refrigerants (of different evaporation temperatures) are adopted for evaporators of the heat pumps to realize tiered temperature drops, and the maximum drop is $1{ }^{\circ} \mathrm{C}$. When the volume of water is sufficient at the outlet, and the returned water has high temperatures, the temperature of water from the 
heat pump will increase merely by $5 \sim 10{ }^{\circ} \mathrm{C}$, the power consumption of the unit deceases and thereby the operating cost is cut.

c) The double-refrigerant technique of the heat pump evaporator is studied. Refrigerant 1 evaporates under high temperatures, and Refrigerant 2 evaporates under low temperatures; combining the two will realize fast temperature reduction, but this technique is difficult to realize and has a high cost.

d) The heat pump evaporator that uses the series flow of full-liquid and half-liquid modes is used to realize fast temperature reduction, and the maximum reduction is to $1{ }^{\circ} \mathrm{C}$.

\section{Conclusions}

By optimizing the thermal system of Heyi Station in the Third Oil Development Plant, this paper analyzes the efficiency and scale of the system, puts forward new ideas for energy conservation and environmental protection in utilization of thermal energy, with a vision to provide guidance for future projects and reach the requirements for energy conservation of Huabei Oil Field Group.

\section{Reference}

1. Zhu Yifei,Dai Jianfei,Zhu Hai,Yang Mei, et al. Application of heat pump technology in Shengli oilfield $[\mathrm{J}]$. Energy Conservation in Petroleum \& Petrochemical Industry,2011(10)

2. Yang Lingyan,Xu Wei,Zhu Qingyu and Xiao Long, et al. Development trend analysis of heat pump technology at home and abroad[J].Heating Ventilating \& Air Conditioning, 2012(8)

3. Zhao Zengmin,Zhao Sumin, $W u$ Qiang, et al.Discussion on Application of Underground Water Source Heat Pump Technology in Tianjin Area[J]. Journal of Geotechnical Investigation \& Surveying,2006(11)

4. Zhang Jiru. Water Source Heat Pump Technology in $\mathrm{H}$ Comprehensive Evaluation Research on the Energy-saving Projects[J].Lanzhou Jiaotong University, ,2017

5. Zhou Qi,Zhao WenxinApplication of solar energy and heat pump technology in wood drying[J].Power Demand Side Management,2017(2) 